\title{
Debates en torno al concepto de "novela histórica”. Propuestas desde el diálogo entre la historiografía y la crítica literaria
}

Debates on the Concept of "Historical Novel". Proposals from the Dialogue between Historiography and Literary Criticism

\section{Gerardo Morales Jasso}

UNIVERSIDAD AUTÓNOMA DE SAN LUIS POTOSÍ, gerardosansa@gmail.com

\section{Víctor Manuel Bañuelos Aquino}

UNIVERSIDAD DE GUANAJUATO, banuelosaquino@gmail.com

En el presente artículo se critica la noción de "novela histórica" desde una perspectiva que converge con la historia que se hace desde la ciencia social. Se cotejan diversos textos sobre "novela histórica" con textos historiográficos para responder, desde la historia, una pregunta que ha sido planteada y respondida en el seno de la crítica literaria y de la historia que se hace desde las humanidades: ¿qué debemos caracterizar como novela histórica? Por lo tanto, desde la teoría de la historia, este texto muestra algunos límites existentes respecto a la generación de interdisciplina entre la historia y la literatura.

PALABRAS Clave: paleonovela, novela historiográfica, historia novelada, ciencias sociales, inconmensurabilidad.

This article presents a critique of the notion of the "historical novel" from a perspective that converges with history as constructed from the Social Sciences. Various texts that deal with the "historical novel" are compared with historiographical texts to answer-from a historical point of view- a question first raised, and answered, in the domain of literary criticism and history as constructed from the Humanities; namely, what kinds of works should be characterized as historical novels? As a result, this text reveals some limits that exist regarding the generation of interdisciplinarity between history and literature from the standpoint of the theory of history.

KEYwords: paleo-novel, historiographic novel, novelated history, social sciences, incommensurability.

Fecha de recepción: 18 de febrero de 2016 / Fecha de aceptación: 11 de julio de 2016 / Fecha de versión definitiva: 13 de julio de 2016

\section{INTRODUCCIÓN}

n torno a la utilización del concepto de "novela histórica" se ha escrito mucho, pero casi siempre desde la matriz disciplinaria de la crítica literaria. Con base en lo anterior, valdría la 
pena preguntarnos: ¡es este concepto una convención literaria o historiográfica? Sea cual sea la respuesta, también vale reflexionar sobre la utilización de este concepto desde la epistemología y la teoría de la historia. Al respecto, quienes estas líneas escriben ponemos en duda si es historiográficamente legítimo llamarla novela histórica desde la epistemología de segundo orden, la teoría de la historia y la crítica literaria, con base también en un nominalismo trascendental kuhniano que dialoga con realismos moderados como el de Ian Hacking, lo que es convergente con un constructivismo moderado. ${ }^{1}$

A través de lo anterior, detectamos un problema en la utilización del término "novela histórica": que la reflexión sobre el mismo ha sido precaria. Epistemólogos como Gustavo Córdoba ya hacían un llamado de atención en contra de esta clase de abusos: "los compromisos con la tradición son efectivos en la ciencia normal, en la medida que liberan a los científicos de la necesidad de examinar continuamente los principios básicos sobre los que se asienta la investigación" así que se dedican "a la resolución de enigmas sobre una base de acuerdos" teórico-metodológicos "que no entra en discusión”. ${ }^{2}$ También se podría agregar que: para que se dé el aprendizaje el alumno ha de someterse a la autoridad de su maestro. "Por su parte, el sometimiento a la autoridad entrańa que la tradición se asimila de manera acrítica" ${ }^{3}$

Para el historiador, la cuestión está entre torear en el terreno del toro: que el sujeto se incorpore "al mundo histórico al que pertenece el objeto” (que es la crítica histórica), o torear en terreno propio: que

${ }^{1}$ Ian Hacking, Representar e intervenir (México: Paidós, unAM, 1996), 132, 133, 303; Juan Pedro Viqueira, "Una historia en construcción. Teoría y práctica de los desfases”, en Anuario del Centro de Estudios Superiores de México y Centroamérica 2000 (San Cristobal de las Casas: Universidad de Ciencias y Artes de Chiapas, Centro de Estudios Superiores de México y Centroamérica, 2002), 344, 348, 353, 359, 376, 378.

${ }^{2}$ Gustavo Córdoba, "Anexo I. Un papel para la historia: Thomas Samuel Kuhn”, en Introducción a la problemática epistemológica. Una perspectiva didáctica de las tensiones en la Filosofia de la Ciencia, Edgardo Datri y Gustavo Córdoba, 222 (Rosario: Homo Sapiens, 2004).

${ }^{3}$ Gustavo Córdoba, "Anexo II. Aportes para una alternativa: Michael Polanyi”, en Introducción a la problemática epistemológica. Una perspectiva didáctica de las tensiones en la Filosofía de la Ciencia, Edgardo Datri y Gustavo Córdoba, 234 (Rosario: Homo Sapiens, 2004). 
el objeto sea "incorporado a la cultura de quien lo hace motivo de su contemplación" (que, en este caso, equivaldría a la crítica literaria). ${ }^{4}$ Por lo tanto, en el presente artículo se busca destacar que lo "histórico" no refiere a lo mismo en la crítica literaria y en la disciplina de la historia.

Aun dentro de la disciplina, la historia es cultivada por diversos autores dentro del campo de las humanidades (E. P. Thompson y Edmundo O'Gorman), mientras que otros la cultivan como una ciencia social (Giovanni Levi y Marc Bloch). ${ }^{5}$ Desde la creación de los primeros departamentos en ciencias sociales en Occidente, a finales del siglo xIX, se ha distinguido entre la ciencia social y la historia. Pero fue hasta los años sesenta y setenta del siglo pasado que se integró la historia a las ciencias sociales, lo cual dio como resultado que en la práctica, los investigadores al hacer historiografía no llegaran a un consenso, de manera que unos la hicieran a partir de métodos y estrategias de las humanidades y otros desde marcos teóricos de las ciencias sociales, lo cual implicó el uso de conceptos de la historia provenientes de diversas tradiciones dando como resultado un "eclecticismo metodológico", que complicó de esta manera el análisis histórico, ya que la historia hecha desde ambas partes puede llegar a ser inconmensurable intradisciplinariamente. ${ }^{6}$

Por lo tanto, aunque la historia es una disciplina compleja, imposible de colocar sin contraargumentos únicamente en una de las ra-

${ }^{4}$ Edmundo O'Gorman, "El arte o de la monstruosidad", El arte o de la monstruosidad y otros escritos (México: Planeta, Conaculta, 2002), 78.

${ }^{5}$ Harvey J. Kaye, "E. Thompson: la formación de la clase trabajadora inglesa", Los historiadores marxistas británicos. Un análisis introductorio (Zaragoza: Prensas Universitarias, 1989), 194; Giovanni Levi, "Sobre microhistoria", en Formas de hacer Historia, Peter Burke et al., 141 (Madrid: Alianza Editorial, 1993); y Carlos Antonio Aguirre Rojas, "La biografía como género histórico", Correo del Maestro (45) (febrero 2000).

${ }^{6}$ Klimovsky indica que "cada contendor, por todos los medios de que dispone, trataría de aclarar su vocabulario, su nomenclatura y las reglas de su lenguaje". Si entre cada disciplina, el vocabulario y los significados son diferentes, "la discusión científica y filosófica, [...] es como un diálogo de sordos en el que cada uno habla con su arquitectura paradigmática sin que el otro disponga de medios para oírlo, en un sentido racional y comprensivo de la palabra” a menos que se dé una conversión. Gregorio Klimovsky, Las desventuras del conocimiento cientifico. Una introducción a la epistemología (Buenos Aires: A-Z editora, 1997), 344, 362 y 363. 
mas dualistas del conocimiento conocidas como ciencias sociales y humanidades, se enfrenta a posturas encontradas entre académicos que se posicionan a sí mismos y posicionan a la historia, entre las humanidades o entre las ciencias sociales. Así que sin caber totalmente en una u otra, es practicada de ambas maneras. ${ }^{7}$ Las propuestas conceptuales que aquí se presentan no son, pues, necesariamente válidas para la literatura o para la historia que se hace desde las humanidades, sino para que sean conceptos analíticos útiles para la historia que se hace desde las ciencias sociales. Por lo tanto, se pretende problematizar si es legítimo el término y significado de novela histórica desde la perspectiva de la historia que se hace desde las ciencias sociales.

La pertinencia de este problema existe porque los historiadores debaten y critican el uso de palabras como moderno, colonial y Renacimiento, pero como gremio, son menos propensos a poner a prueba las definiciones que sientan las bases de sus estudios y, a partir de ello, detectar anomalías, en primera, por cierta carencia de teoría y, en segunda, por el condicionamiento del trayecto para establecer la historia en su etapa de ciencia normal. ${ }^{8}$ Además, cuando nos enfrentamos a un objeto de estudio compartido, habría que aclarar el vocabulario, la nomenclatura y las reglas de su uso contrastando las perspectivas contrapuestas, pues, como lo planteó Marx, la tarea no es la creación de conceptos, sino en tanto que sirvan para captar las relaciones reales. Por eso, antes de llegar al problema de la novela histórica, abordaremos brevemente la relación historia/literatura y también las definiciones que usaremos para analizar el problema planteado. Se partirá de la premisa de que los académicos no deben dar por sentado los conceptos que manejan, sino que han de ser claros acerca del significado que les dan y de que los conceptos usados y sus significados obligan a pensar de ciertas formas. Especialmente, si los conceptos son resultados de lo heterorreferencial. Ante lo cual, es necesario generar autorreferencialidad, ${ }^{9}$

${ }^{7}$ Gerardo Morales Jasso, "El discutible carácter de las formas de hacer historia: ¿ciencias o humanidades? Una propuesta no dualista", Legajos (5) (enero-marzo 2015): 47-70.

${ }^{8}$ Gregorio Klimovsky, Las desventuras, 348, 351.

${ }^{9}$ Harvey Kaye, "E. Thompson”, 185; James Mahoney, "Revisiting General Theory 
pues, "el investigador no puede asumir ciegamente las categorías de los sujetos estudiados". ${ }^{10}$

\section{Historia Y LITERATURA}

La historia es una disciplina que desde la Antigüedad se ha asociado a la retórica, por lo cual se le ha considerado como "un género más de la literatura”. Pero, a pesar de que el producto de la investigación en historia sea una narración escrita; con la incursión de las ciencias sociales ya no podemos decir que la historia se reduce a la retórica, o caracterizarla como un género literario (si así se hiciera, se haría desde lo heterorreferencial). Tanto literatos como historiadores buscan representar experiencias individuales o colectivas, sean éstas habituales o extraordinarias. ${ }^{11}$ Para comunicar, ambas utilizan textos, que son por sí mismas observaciones mediadas de las prácticas sociales concretas. ${ }^{12}$ Posteriormente, los textos no tienen una recepción íntegra, hay entropía y espacio liminal, de modo que los grupos que los reciben los alteran en las comunicaciones y en sus mentes.

Para Walter D. Mignolo, la literatura es un texto conformado por un conjunto de estructuras verbo-simbólicas, reguladas por un metalenguaje de manera explícita o implícita. ${ }^{13}$ Mario Vargas Llosa indica que "la literatura es el reino por excelencia de la ambigüedad.

in Historical Sociology", Social Forces 83(2) (2004): 460; y Margaret R. Somers, "What's Political or Cultural about Political Culture and the Public Sphere? Toward an Historical Sociology of Concept Formation”, Sociological Theory 13(2) (1995): 113, 115.

${ }^{10}$ Juan Pedro Viqueira, "Una historia en construcción", 348.

${ }^{11}$ María Teresa Cortés Zavala, "Historia y literatura: una relación invisible", en $L a$ historia y su relación con otras disciplinas, coord. José Alfredo Uribe Salas y María Teresa Cortés Zavala, 116, 118, 122 (Morelia: umsnh, 2003); Jacques Le Goff, Pensar la historia. Modernidad, presente, progreso (Barcelona: Paidós, 2005), 14 y Giovanni Levi, "Sobre microhistoria”, 136.

${ }^{12}$ Graciela Velázquez Delgado, "Un espacio abierto: la interdisciplina en algunas corrientes historiográficas del siglo xx", en Reflexiones sobre historia e interdisciplina. Planteamientos teóricos, metodológicos y estudios de caso, coord. Graciela Bernal Ruiz, 68 (Guanajuato: Universidad de Guanajuato, 2012).

${ }^{13}$ Walter D. Mignolo, Elementos para una teoría del texto literario (Barcelona: Editorial Crítica, 1978), 35-36. 
Sus verdades son siempre subjetivas, verdades a medias, relativas, verdades literarias que con frecuencia constituyen inexactitudes flagrantes o mentiras históricas". ${ }^{14} \mathrm{Si}$ se toma esto en cuenta, no es de extrañar que el autor literario se valga de toda clase de tropos y estrategias narrativas para velar sus puntos de vista y crear una ficción que parezca veraz al momento de ser leída por su lector. ${ }^{15}$ De ese modo, la literatura se narra como si de verdad hubiese sucedido así, simula que su contenido es verdadero. El lector lee la obra de ficción como si fuera un relato de acontecimientos reales, exigiendo al relato verosimilitud, que es la ilusión de veracidad. Es decir, el autor, que sabe que "lo que cuenta es literalmente falso, hace como si fuese verdadero, y el lector, aunque sabe que los hechos novelescos son irreales, los acepta como reales [...] Al final, vuelve a la realidad desde la irrealidad del relato, pero lo real no será ya como antes, pues, si la narración está lograda, se habrá transformado o enriquecido con la ficción o mostrará otra visión o dimensión". ${ }^{16}$

Así, un texto literario representa el presente y el futuro de una comunidad imaginada (tanto en el sentido que usa la palabra Benedict Anderson como en el sentido de ficticio) metabolizando metáforas y ambigüedades de una forma en que la ciencia y la historia no lo permite, pues, según Thomas Kuhn, para quien la ciencia comparte una axiología con la historia, "La narración histórica debe hacer plausibles y comprensibles los acontecimientos que describe". De modo que "la historia es una empresa explicatoria [...] que induce a comprender, y por eso debe mostrar no únicamente hechos sino también conexiones que hay entre ellos". ${ }^{17}$

Lo que implica que los géneros literarios son textos sociales que no son ajenos a la realidad, sino que son parte de ella, se inspiran en hechos reales y a partir de ellos construyen hechos ficticios. Por lo 24,25 .

${ }^{14}$ Mario Vargas Llosa, La verdad de las mentiras (Madrid: Punto de Lectura, 2007),

${ }^{15}$ Fernando del Paso, "Novela e Historia”, en Historia y novela histórica, coord. Conrado Hernández López, 97-99 (México: Colegio de Michoacán, 2004).

${ }^{16}$ Manuel Alberca, "En las fronteras de la autobiografía", en II Seminario de "Escritura autobiográfica”, coord. Manuela Ledesma Pedraz (Jaén: Universidad de Jaén, 1999).

${ }^{17}$ Thomas S. Kuhn, La tensión esencial. Estudios selectos sobre la tradición y el cambio en el ámbito de la ciencia (Madrid: Fondo de Cultura Económica, 1982), 29, 39, 151-185. 
tanto, los géneros literarios son factibles de análisis por parte de análisis del discurso, sociología del conocimiento, teoría de la recepción, hermenéutica del lenguaje y estudios culturales.

Por otro lado, la historia, parafraseando a Marc Bloch -quien rechazó definir la historia como la ciencia del pasado- es la disciplina científica que estudia a la humanidad, sus obras e ideas en el tiempo, lo que coincide con la visión plural de Fernand Braudel, para quien "la historia es la suma de todas las historias posibles: una colección de oficios y de puntos de vista, de ayer, hoy y mañana”. ${ }^{18}$ Lo que implica: 1) que el pasado es condición necesaria, pero no suficiente de lo histórico, pues, "La historia no puede lógicamente separar el estudio del pasado del estudio del presente y del futuro", como indicó la revista Past and Present desde 1952. ${ }^{19}$ Por eso, si, por ejemplo, actualmente se hace poca historia posrevolucionaria en México es porque los historiadores no se han comprometido lo suficiente con la historia inmediata y con la historia del tiempo presente como sí lo hicieron Servando Teresa de Mier y Roque Estrada, o los investigadores de Annales, que pusieron en correlación el pasado y lo contemporáneo. ${ }^{20}$ 2) Que si como menciona O'Gorman, "por historia entendemos el proceso entero del vivir humano", siendo la literatura una necesidad de la vida moderna, ésta ha impactado y ha sido impactada por el devenir de las sociedades y por lo tanto es pertinente para la historia; especialmente en lo que concierne a las condiciones de producción y circulación de la literatura, que forman parte de la historia social del conocimiento como la que estudia Peter Burke. ${ }^{21}$

${ }^{18}$ François Dosse, "Los tiempos de Marc Bloch y Lucien Febvre", La historia en migajas. De Annales a la nueva historia (México: Universidad Iberoamericana, 2006), 67; y Fernand Braudel, La historia y las ciencias sociales (Madrid: Alianza Editorial, 1999), 75.

${ }^{19}$ Jacques Le Goff, Pensar la historia, 196 y Carlos Barros, "Oficio de historiador, ¿nuevo paradigma o positivismo?”, Historia a Debate, http://cbarros.com/vistacb/?link=http://h-debate.com/wp-content/old_debates/cbarros/spanish/articulos/nuevo_paradigma/oficio.htm

${ }^{20}$ François Dosse, "Los tiempos de Marc Bloch", 68, 70 y Luis Medina Peńa, "Historia contemporánea ¿̇tema de historiadores?”, en Cincuenta años de investigación histórica en México, coord. Gisela von Wobeser, 296 (México: UnAM, UG, 1998).

${ }^{21}$ Edmundo O'Gorman, "La historia como búsqueda del bienestar. Un estudio acerca del sentido y el alcance de la tecnología", El arte, 22; Franco Moretti, La literatura 
Según Michael Denning, la novela "guarda una relación incierta con la política y los movimientos sociales", ${ }^{22}$ no sorprende entonces que Lucien Febvre en su Rabelais haya intentado responder ¿quién lee y qué se lee? Así como ¿para qué se escribía y para qué se leía? Tampoco sorprende que para Bloch el arte y la literatura hayan sido fuentes importantes para reconstruir las mentalidades del pasado y que para entender propiamente la historia sea necesario reconstruir los lentes a través de los que los escritores miran el mundo y sea necesario que el historiador considere como evidencias la manera de pensar de los autores, su bagaje cultural, sus posturas políticas, las justificaciones que usa al escribir, los valores que plasma y los que rechaza, así como los estereotipos a los que recurre. ${ }^{23}$

Si miramos con atención los párrafos anteriores tenemos que la historia es escritura, pero que la literatura pertenece a la Historia. Es necesario distinguir la historia-ontología (res gestae), de la historiacomunicación (rerum gestarum); siguiendo a José Gaos, a esta última nos referiremos de ahora en adelante como historiografía, pues, el conocimiento sobre la realidad forma parte de la realidad y su escritura da sentido a su investigación, lo que representa fragmentos de la Historia. De modo que sólo muchas historiografías sólidamente investigadas pueden tender a la Historia. ${ }^{24}$

Por lo tanto, no partiremos de un posicionamiento epistemológico en el que la historia es sólo representación desvinculada del acontecer. Tal posicionamiento no sólo desconoce lo que está afuera de la conciencia o de la comunicación, sino que lo niega.

vista desde lejos (Barcelona: Morbot Ediciones, 2005), 18 y Peter Burke, Historia social del conocimiento. De Gutenberg a Diderot (Barcelona: Paidós, 2002).

${ }^{22}$ Franco Moretti, La literatura, 18.

${ }^{23}$ François Dosse, "Los tiempos de Marc Bloch”, 86; Georg Iggers, "Francia: la escuela de los Annales", La historiografia del siglo XX. Desde la objetividad cientifica al desafio posmoderno (Santiago de Chile: Fondo de Cultura Económica, 2012), 102; John Burrow, "Un consenso profesional: la influencia alemana", Historia de las Historias. De Herodoto al siglo XX (Barcelona: Crítica, 2009), 547 y Miguel Ángel Guzmán López e Ignacio Camarena Navarro, "Entre Julio Verne", 186.

${ }^{24}$ Armando Saitta, Guía crítica de la historia y de la historiografia (México: Fondo de Cultura Económica, 1989), 12; y Silvia Pappe y María Luna Argudín, Historiografía critica. Una reflexión teórica (México: UAM-A, 2001), 95. 
El conocimiento de la Historia no implica que la historiografía pueda reflejarla tal como fue. Pero significa que el río del conocer de la historia, que fluye lentamente, no puede alejarse de la Historia ni puede avanzar más rápido que aquella. De hacerlo caería en especulaciones en torno a su objeto de estudio que entran al campo de la ficción y salen de su matriz disciplinar como ciencia histórica. Entonces, la literatura pertenece a la Historia pero la historiografía está formada de textos que buscan representar la Historia y pertenecen a su vez a ella, pues, la historiografía busca captar la Historia como una unidad compleja, que respeta la pluralidad que en ella existe y evita los determinismos. ${ }^{25}$ De modo que los pactos historiográfico y novelesco son distintos, presentan diferentes valores y compromisos estéticos y de veracidad, por lo que la novela histórica se encuentra entre el contrato veredictorio y estético sin perseguir uno de los dos caminos, pero yendo entre ellos. Por su parte, el historiador no tiene la libertad del novelista, lo que reafirma para Jacques Le Goff que la historia no es un género literario. Así que, contrario a lo que plantea François Dosse, el camino más eficiente entre la historia (historiografía) y la Historia no es la imaginación, sino la investigación crítica. ${ }^{26}$ Pues, aunque el historiador hace uso de la narrativa y la imaginación, esta última la utiliza con base en evidencias para realizar inferencias y así llegar a conclusiones y la narrativa le permite realizar razonamientos causales principalmente abductivos. ${ }^{27}$

Tenemos, pues, que la literatura y la historiografía son diferentes formas de representar la realidad, ya que, siguiendo a Luis González y González, la primera puede darse el lujo de imaginar, con base en su experiencia personal, cada elemento que va a representar en su

${ }^{25}$ Edmundo O'Gorman, "La historia como búsqueda”, 218.

${ }^{26}$ François Dosse, "La biografía, un género impuro", El arte de la biografía (México: UIA, 2007), 117, 118; Manuel Alberca, "Umbral o la ambigüedad autobiográfica”, Círculo de Lingüistica Aplicada a la Comunicación (CLAC) (50) (2012): $11 \mathrm{http} / / /$ pendientedemigracion.ucm.es/info/circulo/no50/alberca.pdf (Fecha de consulta: 20 de marzo de 2014) y Jacques Le Goff, Pensar la historia, 40, 41. Compárese con la perspectiva de Duby allí mismo.

${ }^{27}$ James Cracraft, "History as philosophy", History and Theory (54) (febrero 2015): 51-53. 
narración, mientras que la segunda debe construir la propia a partir de las pistas e indicios que le ofrece la información recopilada en un archivo. $^{28}$

Así que la historia no es sólo una metáfora de la realidad, sino que persigue ser un modelo de la misma. En la historiografía, la lógica narrativa no puede ser más importante que el apego a la evidencia, que coteja y critica. ${ }^{29}$ Toda historia debe estar inmersa en la teoría de la comunicación, reducir la entropía y el espacio liminal; mientras que en la literatura el escritor puede dar rienda suelta a su imaginación, jugar con la analogía y la metáfora con una finalidad estética, decir verdades con ficciones e inventar inspirado en verdades, o sea que aunque la literatura hunde sus raíces en la experiencia humana, la transforma. ${ }^{30}$

En cuanto a sus estrategias narrativas, el novelista escribe con una estructura textual, una trama narrativa y elementos dramáticos, vinculados a su contexto. Crea sus personajes: 1) a partir de su realidad, una realidad cercana o lejana; 2) fusiona un ser inexistente y elementos de la realidad a su alcance; y 3) se proyecta él mismo, resaltando elementos de su consciencia y de su entorno. Lo que hace que en una novela u otro tipo de obra de arte los personajes actúen de forma parecida a como lo hacen las personas de su época, su cultura y su mundo. Por eso no sorprende que para Manuel Alberca toda novela sea autobiográfica. Aunque también, el texto que escribe el historiador está condicionado por las formas narrativas de su gremio y de la época. ${ }^{31}$

${ }^{28}$ Luis González y González, "La novela histórica verídica”, en Historia y novela histórica, 25.

${ }^{29}$ Ana María Alba Villalobos, "Géneros de frontera entre la historia y la literatura. Un espacio obligado para el trabajo interdisciplinario" (Guanajuato: Universidad de Guanajuato, 2012), 27.

${ }^{30}$ François Dosse, "La biografía", 59 y Mario Vargas Llosa, La verdad de las mentiras, $16,17,21$.

${ }^{31}$ Manuel Alberca, "En las fronteras”; María Teresa Cortés Zavala, "Historia y literatura”, 124, 125; Silvia Pappe y María Luna Argudín, Historiografía crítica, 123; María Teresa Cortés Zavala, "Historia y literatura”, 121 y Ruben Gomes Lacerda, "Interstícios e interfaces entre a história e a literatura: uma nova velha discussão", en Escrita da história, org. João Edson de Arruda Fanaia, Osvaldo Mariotto Cerezer, Renilson Rosa Ribeiro (Cáceres: unemat, 2010). 
Pero esto no debe llevarnos a decir que la literatura refleje la realidad, sino a "entender que la relación de la obra con el contexto se da en distintos niveles y no es directa, sino simbólica y sesgada" ${ }^{32}$ Tampoco podemos decir que la historia refleje la realidad, o que lo hace la física (por lo que rechazamos el realismo ingenuo), ${ }^{33}$ sino que hacen referencia a ella con un alto grado de iconicidad, que desde la semiótica heredera de Charles Sanders Peirce significa parecido con el referente. Mientras la literatura busca verosimilitud, la historia busca veracidad y esta búsqueda se lleva a cabo como una obra abierta y sin finalizar allí donde la novela es una obra cerrada y finalizada. También en eso radica la diferencia entre la historia y la literatura, que dentro de las posibilidades de lo icónico, la última está más apegada a lo metafórico que a lo modélico, mientras que la historia-narración figura la Historia-realidad en tanto modelo, no en tanto metáfora. Dicho lo anterior en el sentido de que:

1. En un texto de historia se puede criticar el mal uso de conceptos y citas o conceptos mal definidos, como por ejemplo E. P. Thompson criticó a Perry Anderson y Tom Nairn. ${ }^{34}$

2. No se puede reabrir una novela y reescribirla, mientras que la historia, que surge de una investigación y se plasma en una escritura, invita a su cuestionamiento, así que se puede a) mostrar que no hubo descubrimiento sino invención de América y b) corregir datos, como que el Grito de Dolores fue en la madrugada del 16 de septiembre y no la noche del $15 .{ }^{35}$

Sin embargo, no podemos, a menos que seamos falaces, decirle a George R. R. Martin que en el juicio por combate a Tyrion Lannister no murió Oberyn Martell, o que en el evento llamado la boda roja no sucedió lo que se narra en Tormenta de espadas. Lo que sí podemos notar es que para describir este episodio de su fantasía se

32 "Presentación", en Escrita da história, 9.

${ }^{33}$ Juan Pedro Viqueira, "Una historia en construcción”, 345, 347.

${ }^{34}$ Crítica que está sintetizada en Harvey J. Kaye, “E. Thompson”, 175, 184.

${ }^{35}$ Silvia Pappe y María Luna Argudín, Historiografía crítica, 72. Puede verse la tesis contra la historia whig de la Independencia: Gerardo Morales Jasso, "La creación de México. Una revisión historiográfica sobre la Independencia” (Tesis de Licenciatura en Historia, Universidad Autónoma de San Luis Potosí, marzo 2013). 
inspiró parcialmente en un evento de la historia escocesa conocida como la "cena del toro negro".

\section{"Novela histórica" o "NOVELA historiográficA"}

Podemos jugar o trabajar con la confusión en torno al término "novela histórica" ${ }^{36}$ De todas formas, proceder de un modo o de otro será impactado por la presuposición de que existe algo llamado novela histórica y que presenta ciertas características. Sin tal presuposición no se puede avanzar en la investigación sobre tal tipo de novela. ${ }^{37}$ Sin embargo, en este trabajo se critica la noción de novela histórica a través de cotejar la información presentada en los párrafos anteriores con diversas respuestas que se dan a la pregunta ¿qué caracterizamos como novela histórica?

Según Franco Moretti, la novela histórica se inventó en el siglo XIX, puede tomarse como género o como subgénero de la literatura. Antonio Rubial la define como literatura de tema histórico. ${ }^{38}$ Avrom Fleishman la define a partir de las novelas cuya acción sucede en un pasado separado del autor por dos generaciones. David Cowart propone como definición: "ficción en que el pasado figura con cierta importancia”. Anderson Imbert definió la novela histórica como aquella que cuenta una acción ocurrida en una época anterior a la del novelista. Mientras que para Seymour Menton, la novela histórica es "un subgénero esencialmente escapista" cuyo fin principal fue "recrear fidedigna y bellamente ciertas épocas del pasado". Influido por los tres autores anteriores, Menton indica que la categoría de novela histórica ha de ser reservada "para aquellas novelas cuya acción se ubica total o por lo menos predominantemente en el pasado, es decir, un pasado no experimentado por el autor". ${ }^{39}$

${ }^{36}$ Margaret R. Somers, "What's Political”, 130.

${ }^{37}$ Gregorio Klimovsky, Las desventuras, 213.

${ }^{38}$ Franco Moretti, La literatura, 30, 49-51 y Antonio Rubial, "Historia 'literaria' versus Historia 'académica", en El historiador frente a la historia. Historia y literatura, $\mathrm{F}$. Navarrete, A. Rubial et al., 42 (México: unAm, 2000).

${ }^{39}$ Seymour Menton, "La nueva novela histórica: definiciones y orígenes", en $\mathrm{La}$ nueva novela histórica de la América Latina, 1979-1992 (México: Fondo de Cultura Económica, 1993), 32, 33, 37, 51. 
El problema de las anteriores definiciones para la historiografía es que le dan sentido a la novela histórica desde la literatura. Por lo que para la historiografía son definiciones heterorreferenciales y habría que plantear definiciones autorreferenciales que sean congruentes con la historia. Menton planteó que la novela histórica es "escapista" por ser un espacio ambiguo, de manera que el término de novela histórica dependería tanto de la literatura como de la historiografía. Lo cual implica entre otras cosas:

1. Que no determinará si una novela es histórica o no el que hubiera un personaje histórico importante, ni entender los grandes personajes como motores de la historia. El que esto definiera lo histórico, sería anacrónico para los estudios históricos luego de que los historiadores aceptaran la idea de Giambattista Vico, retomada por Jules Michelet de que la historia no estaba confinada a los hechos de generales, nobles y monarcas, sino que "la gente ordinaria jugaba un papel decisivo en el curso de la historia". ${ }^{40}$ Incluso ahora podemos decir, tomando como referencia la obra de Le Goff, que todo es historia porque nada "por insignificante que sea en apariencia, es indigno de la curiosidad histórica" ${ }^{41}$ y con Eric Hobsbawm que "No hay ningún pueblo sin historia o que se pueda comprender sin ella". ${ }^{42}$

2. Aceptar que ya se ha superado la visión de historia como pasado únicamente, pues, todo presente es histórico y no debería hacer falta pregonar su historicidad luego de tantos años de existencia de la definición de Marc Bloch. ${ }^{43}$

Por lo tanto, ninguna de las definiciones heteroreferenciales de novela histórica satisfarían a la historiografía. Incluso habríamos de ir más allá de la afirmación de Menton de que en "el sentido más amplio, toda novela es histórica, puesto que, en mayor o menor

\footnotetext{
${ }^{40}$ Brian Hamnet, "Historias ficticias: el dilema de los hechos y la imagen en la novela histórica del siglo xix", Historias (69) (enero-abril de 2008), 99.

${ }^{41}$ Jacques Le Goff, Pensar la historia, 23, 138.

${ }^{42}$ Eric Hobsbawm, "Todos los pueblos tienen historia”, Sobre la historia (Barcelona: Biblioteca de bolsillo, 2004), 177.

${ }^{43}$ Benjamín E. Mayer, "Perdurabilidad de la historia en Jacques Derrida", en Cincuenta años, 62.
} 
grado, capta el ambiente social de sus personajes, hasta de los más introspectivos". ${ }^{44}$ Desde la perspectiva de la ciencia histórica, incluso novelas sobre el presente y el futuro serían históricas, es decir, dentro de la Historia y pertinentes para la historiografía porque toda representación de un cronotopo (concepto desarrollado por Mijail Bajtin que explica la representación de los entramados específicos del espacio-tiempo) sería histórica. En Estética de la creación verbal, Bajtin lo definió como "el grado intrínseco de conexión en las relaciones temporales y espaciales en la literatura”. Para él, el cronotopo literario es más difícil de entender que el histórico, pues, el histórico es real. ${ }^{45}$ Como toda novela está en la Historia, toda novela sería histórica, haga uso de anacronismos o sea en sí misma una ucronía, sea una novela futurista o llegue a crear mundos y universos como lo hicieron J. R. R. Tolkien y C. S. Lewis. Dicho esto, estarían entre las novelas históricas tanto las novelas con cronotopos reales como las que los tienen ficticios ya sea que sus narraciones representen acontecimientos que se desarrollan realista o ficcionalmente. Desde la historiografía, toda novela sería novela histórica; lo que hace innecesario añadirle tal adjetivo.

Como toda novela es escrita en la Historia, toda novela sería histórica, por lo que sería inútil cuestionarla como hija de su tiempo. La que vale la pena cuestionar es la novela historiográfica; una novela que a pesar de contar con invenciones en cuanto a los personajes o acontecimientos o cronotopos, los plasma con cierta iconicidad (o veracidad, además de la verosimilitud que se hallaría en otras novelas) haga referencia o no a acontecimientos o personajes que tienen o tuvieron existencia. Ya sea que su línea argumental sea ficticia, pero haya un cronotopo referenciado en la realidad o que haya episodios inspirados en sucesos reales en un cronotopo ficticio, habría una novela historiográfica, es decir, una novela con referencias a la realidad extraliteraria. Por lo tanto, a continuación, donde los autores citados hablaron de novela histórica, plasmaremos novela historiográfica. Lo que nos vincula a la definición de "novela histó-

${ }^{44}$ Seymour Menton, "La nueva novela”, 31, 32.

${ }^{45}$ Silvia Pappe y María Luna Argudín, Historiografía crítica, 21, 44, 77. 
rica” de María Cristina Pons, quien la define como una novela en la que la invención no puede ser total, que debe remitir a un periodo o evento real y a la de Celia del Palacio, quien influida por Pons critica la definición de Menton y prefiere no usar "novela histórica", sino escritos donde se une la ficción y la historia. De forma parecida a como lo hace Grützmacher, quien indica que la metaficción historiográfica busca equiparar historia y ficción. ${ }^{46}$

Sin embargo, las definiciones de Menton, Fleishman e Imbert plantean otro problema que requiere solución, pues, si ya no podemos nombrar novela historiográfica únicamente a la novela que se caracteriza porque lo que narra sucede en una época anterior a la del novelista, ¿cómo podemos llamarla? Proponemos que para crear un término congruente con la historia y la literatura no se recurra al prefijo "pre", que puede connotar desventajas valorativas; sino al prefijo "paleo", del griego $\pi \alpha \lambda \alpha \iota \varsigma_{\varsigma}$ (antiguo). Así, las definiciones de Menton, Fleishman e Imbert se referirían a las paleonovelas; que con las novelas del tiempo presente (las que ocurren tanto durante la vida del novelista como en otro tiempo) y con las novelas cuyos narradores están en el presente, pero lo narrado ocurre en el pasado; formarían una subclase de las novelas historiográficas.

${ }^{46}$ Celia del Palacio Montiel, "La novísima novela histórica en México. Una revisión de las más recientes tendencias", en Negociando identidades, traspasando fronteras, ed. Susanne Igler y Stauder Thomas, 202, 203 (Madrid: Iberoamericana-Vervuert, 2008); y Lukasz Grützmacher, "Las trampas del concepto 'la nueva novela histórica' y de la retórica de la historia postoficial”, Acta Poética 27(1) (primavera 2006): 141-167. https://revistas-filologicas.unam.mx/acta-poetica/index.php/ap/article/view/193/192 (Fecha de consulta: 3 de marzo de 2014). El término metaficción aquí no se abordará porque el prefijo meta se usa de forma diversa según se vincule a una palabra (metalenguaje como lenguaje sobre el lenguaje, metanarracciones como grandes narraciones que están en el fondo de las narraciones y metahistoria como poética de la historia; sólo para mencionar unos de sus significados) dando lugar a la polisemia. El concepto es de por sí complicado y su falta de univocidad lo hacen problemático, pero no inútil para referirse a las obras que juegan entre la ficción y la historia. Otra de las autoras que lo usa es Ana Corbalán en "Metaficción historiográfica en la novela española del siglo xxi: Hacia una reconstrucción del pasado nacional”, Cuaderno Internacional de Estudios Humanisticos y Literatura, vol. 16 (otońo 2011): 22-34, donde inicia con una cita de Todorov en la que plantea que el estatus de la literatura es el de la ficción, para hablar de una literatura que confunde al lector, pues, no se sabe qué es falso y qué es verdadero. 
En torno a este tipo de problemáticas, autoras como Eugenia Revueltas hacen hincapié en que tanto la historiografía como la literatura son saberes narrativos, haciendo una distinción en cuanto al hecho de que, según Alfonso Reyes, existen dos literaturas: una literatura propiamente dicha, con el fin de crear una realidad poética; $y$, por otro lado, existe una ancilar, que sirve como vehículo de la filosofía y la historia. ${ }^{47}$ De manera que es posible identificar una literatura que tiene como fin último desarrollar una experiencia estética en contraposición con otra que tiende más a la veracidad. El problema es precisamente que en la novela historiográfica se unen la ficción y la historia en diversos grados y estilos, lo que crea un sinnúmero de problemas para la historiografía y para la literatura.

\section{Perspectivas COMPLEMENTARIAS SOBRe LA NOVELA HISTORIOGRÁFICA}

Dentro del concepto de "novela histórica", el uso del adjetivo "histórica" ha sido en ocasiones utilizado abusivamente y da como resultado una inercia en la que la reflexión teórica de la historia ha estado ausente. Para Mario Vargas Llosa decir que una historiografía es novelesca es vejarla, insinuar que no es seria. ${ }^{48}$ De modo que sabemos que la novela no es novela si es historiografía y la historiografía no lo es si se novela, de modo que la novela histórica es, junto a las memorias y las autobiografías, parte de los "textos parahistoriográficos". ${ }^{49}$ ¿Entonces para qué existen las novelas historiográficas? Menton indica que:

Además de divertir a varias generaciones de lectores con sus episodios espeluznantes y la rivalidad entre los protagonistas heroicos y angelicales y sus enemigos diabólicos, la finalidad de la mayoría de estos novelistas fue contribuir a la creación de una conciencia nacional familiarizando a sus lectores

${ }^{47}$ Eugenia Revueltas, "Historia y literatura. Entre el conocimiento y el saber", en Historia y novela histórica, 273-275.

${ }^{48}$ Mario Vargas Llosa, La verdad de las mentiras, 21.

${ }^{49}$ Álvaro Matute, "La historia inmediata", Revista de la Universidad de México (492493) (enero-febrero 1992): 62. 
con los personajes y los sucesos del pasado; y a respaldar la causa política de los liberales contra los conservadores, quienes se identificaban con las instituciones políticas, económicas y religiosas del periodo colonial. ${ }^{50}$

Rubial, por su parte, indica que la novela histórica rescata lo que no dejó vestigios, lo que a algunos historiadores parece intrascendente. Enrique Serna muestra que la novela historiográfica puede ser usada como espacio de denuncia por lo que pueden subvertir la imagen tradicional de héroes y villanos; problematizar su representación maniquea; y jugar con la tensión figuras míticas/figuras históricas/figuras desmitificadas. ${ }^{51}$ Por otro lado, Lukasz Grützmacher plantea que los acontecimientos son algo que sucedió y los hechos son algo construido que representa el acontecimiento, por lo que "no existe una diferencia fundamental entre la creación de los hechos ficticios en una obra literaria y la construcción de los llamados hechos 'históricos' en un texto historiográfico" así que la novela historiográfica descubre mecanismos de la Historia hasta ahora bien ocultos y se opone a la historia oficial; aduciendo que el discurso histórico no es más verídico que el novelístico. ${ }^{52}$ Lo que coincide con lo que planteó Valeria Grinberg, para quien lo que llamamos novela historiográfica "amplía la visión de lo que es considerado como histórico a la vida privada y a lo cotidiano" con lo que recupera "el pasado no canonizado", dándole lugar a las voces desoídas por la historia oficial. ${ }^{53}$ Se postula además que pone a interactuar memoria, historia y ficción, que busca recuperar la memoria, así como reconstruir y reescribir la historia. ${ }^{54}$ Ante lo cual, habría que responder que:

1. La novela historiográfica, haciendo referencia a Bernard Lewis, no sería una historia rescatada, recordada o descubierta, sino

${ }^{50}$ Seymour Menton, "La nueva novela", 36, 41.

${ }^{51}$ Antonio Rubial, "Historia 'literaria”, 58 y Enrique Serna, "Santa Anna en la historia y en la ficción", en Historia y novela histórica, 168, 169, 181, 182.

${ }^{52}$ Lukasz Grützmacher, "Las trampas”, 148, 150, 160, 163.

${ }^{53}$ Valeria Grinberg Pla, "La novela histórica de finales del siglo xx y las nuevas corrientes historiográficas", Áncora (11 marzo 2001), en http://wvw.nacion.com/anco$\mathrm{ra} / 2001 / \mathrm{marzo} / 11 /$ historia2.html (Fecha de consulta: 3 de marzo de 2014).

${ }^{54}$ Ana Corbalán, "Metaficción historiográfica”, 22, 32. 
una inventada, de modo que no rescata lo intrascendente, sino que valora el olvido y lo inventa creativamente. ${ }^{55}$

2. Como hace Le Goff podemos decir que el hecho histórico "no es un objeto dado puesto que resulta de la construcción de lo histórico". Pero que con todo y su constructivismo, Le Goff espeta contra Heidegger que la historia no es una novela y que cuando el filósofo mencionó que "la historia no sería sólo la proyección por parte del hombre del presente en el pasado, sino proyección de la parte más imaginaria de su presente, la proyección en el pasado del porvenir elegido, una historia novelada, una historia-deseo hacia atrás", está elevando a filosofía antiintelectualista la historiografía nacionalista del siglo pasado. ${ }^{56}$

3. Existe una diferencia fundamental entre los hechos de una obra literaria e historiográfica, pues, aunque ambas pueden descubrir con investigación, mientras la primera no puede dejar de ser doxa (opinión), la segunda busca ser episteme (conocimiento) al ajustarse continuamente a los datos surgidos por investigación. ${ }^{57}$

4. Desde un perspectiva racional y crítica de la historia, el historiador no debe transmitir la historia como fundamento ideológico político para el presente, ni enseñar y difundir la historia con la finalidad de promover la adhesión emocional a una determinada identidad nacional (ambas propias de una historia whig). Tampoco puede el historiador mostrar un presente terminal, resultado del proceso de formación de una nación que más que un proyecto de futuro es un mandato de aceptación y conservación, desde un sentido de completitud de la historia. ${ }^{58}$ Por lo tanto, ha habido y hay manipulaciones en la historiografía, de forma que bajo el nombre de

${ }^{55}$ Karen Sanders, "La tradición y la nación”, en Nación y tradición. Cinco discursos en torno a la nación peruana, 1885-1930, 83-122 (Lima: Pontificia Universidad Católica del Perú, Fondo de Cultura Económica, Fondo Editorial de Cultura, 1997).

${ }^{56}$ Jacques Le Goff, Pensar la historia, 11, 31.

${ }^{57}$ Juan Pedro Viqueira, "Una historia en construcción”, 368.

${ }^{58}$ Ramón López Facal, "La enseñanza de la historia, más allá del nacionalismo", en Usos públicos de la Historia, ed. José Carreras Ares y Carlos Forcadell Álvarez (Madrid: Marcial Pons Ediciones de Historia, 2003), 223-255 y Pilar Maestro González, "El modelo de las historias generales y la enseńanza de la historia: límites y alternativas", en Usos públicos de la Historia, 203. 
historia existen usos públicos de la historia que crean y se basan en tradiciones. Así que hay que diferenciar entre historia y usos públicos de la historia, donde el último implica las manipulaciones de la historia para justificar el presente y proyectos a futuro, que sería más bien a lo que se oponen los autores de algunas novelas históricas.

5. Si bien muchos pueden hacer historia oficial (que es un uso público de la historia que sirve para justificar el statu quo actual) y muchos la hacen, de modo que los historiadores y el Estado llegaron a tener los mismos objetivos vinculados al nacionalismo y a la pedagogía cívica patriótica; la historia profesional busca desafiar y superar la historia oficial..$^{59}$

A fines del siglo XIx y principios del xx el eje central de la historia era principalmente la historia política. Hoy existen otros tipos de historia, por ejemplo: la poscolonial que critica la historia patria; los estudios subalternos reconocen la centralidad de los grupos subordinados y rectifica el sesgo elitista de diversas investigaciones académicas; la historia desde abajo busca representar lo sucedido y realizado por personas que no escribieron sobre aquello; la microhistoria, que no busca crear la ilusión de realidad con sus textos, acepta el límite que existe entre realidad y su comprensión de modo que explora las implicaciones gnoseológicas y las transforma en un elemento narrativo; y la historia de la vida cotidiana, que se interesa por las relaciones familiares, las prácticas, los hábitos, la rutina, sus rupturas, el uso del tiempo libre, etcétera. ${ }^{60}$ Hay actualmente también historia ambien-

${ }^{59}$ Carlos Antonio Aguirre Rojas, "La biografía"; François Dosse, "La prehistoria de Annales", La historia en migajas. De Annales a la nueva historia (México: Universidad Iberoamericana, 2006, 42, 44.

${ }^{60}$ John Burrow, "Un consenso profesional", 538; Saurabh Dube, "Identidades culturales y sujetos históricos: estudios subalternos y perspectivas poscoloniales", Estudios de Asia y África 45(2) (mayo-agosto, 2010): 255; Harvey J. Kaye, "Introducción", Los historiadores marxistas británicos. Un análisis introductorio (Zaragoza: Prensas Universitarias, 1989), 7; Carlo Ginzburg, "Microhistoria: dos o tres cosas que sé de ella", Manuscrits (12) (enero 1994): 35 y Pilar Gonzalbo Aizpuru, "En torno a intimidades y rutinas la nueva historiografía de lo cotidiano", en Cincuenta años de investigación histórica en México, coord. Gisela von Wobeser, 69 (México: UNAM, UG, 1998). Gonzalbo continúa con las características de la historia de la vida cotidiana: "supervivencia de quienes apenas tuvieron acceso a un mínimo de bienes materiales y el derroche de quienes vivieron en el lujo y la opulencia, las manifestaciones de duelo y los festejos públicos y privados, gestos, 
tal, historia del deporte, historia de la locura e historia cultural, esta última representa un reencuentro con la literatura.

Hay, entonces, historiografías que tienen funciones que la novela historiográfica plantea como suyas; sin embargo, sería imperialista indicar desde la historiografía que por eso la novela historiográfica no tiene ya razón de ser. Buscando tener calidad estética, la literatura puede representar una realidad y su imaginario. ${ }^{61}$ Contrario a lo que se plantea desde el dualismo cartesiano, la literatura no sólo muestra verdades espirituales. ${ }^{62}$ Carlo Ginzburg destaca que Tolstoi tuvo una capacidad extraordinaria para comunicar al lector "la certeza física, palpable, de la realidad" lo que "parece incompatible con la idea, propiamente decimonónica” de historia. Para él, “Tolstoi supera la distancia inevitable entre los indicios fragmentarios y distorsionados de un acontecimiento (una batalla, por ejemplo), y el propio acontecimiento". ${ }^{63}$ En su Guerra y Paz, Tolstoi investigó sobre Napoleón, aunque eligió mostrar algunos de sus rasgos y calló otros, de modo que la construcción de la narrativa en esta novela refleja al Napoleón de Tolstoi, pero no directamente a Napoleón. ${ }^{64}$

actitudes, conductas y prejuicios propios de cada grupo y mutuas influencias en los procesos de transculturación".

${ }^{61}$ Franco Moretti, La literatura, 90 y Ana María Alba Villalobos, "Géneros de frontera”, 29, 30. Moretti indica también aquí que para todo género y subgénero literario hay un momento en el que ya no está en condiciones de representar la realidad que le es contemporánea, y cuando eso sucede el género se desintegra o le da la espalda a la realidad en nombre de la forma, un dato que es importante para las discusiones que realizan autores como Grützmacher, Menton y Del Palacio en los textos citados.

${ }^{62}$ Esto puede sonar un tanto contradictorio epistemológicamente desde el momento que se plantea que hay que salir del dualismo, pero se sigue separando entre ciencias y humanidades de forma dualista. Reproducimos provisionalmente la separación entre una y otra porque hasta ahora, la historia ha operado en esta distinción, aunque existe una alternativa, el sistemismo.

${ }^{63}$ Carlo Ginzburg, "Microhistoria", 35. Nótese que a través del estudio de las novelas de Vicente Riva Palacio, José Ortiz Monasterio llega a una conclusión similar, indicando incluso que las novelas históricas le permitieron alcanzar a Riva Palacio "una nueva manera de comprender el pasado" convergente con el historicismo alemán sin haber leído a los historiadores de tal corriente (José Ortiz Monasterio, "Dos discursos patrios de Vicente Riva Palacio. Un caso para evaluar la aportación de la novela histórica como método de conocimiento", Historias (69) (enero-abril de 2008): 57, 67, 61, 68, 79.

${ }^{64}$ E. L. Doctorow, "Apuntes sobre historia de la ficción ¿Quién cambiaría la Ilíada por la "verdadera” fuente histórica?", Historias (69) (enero-abril 2008): 5. 
Por su parte, Federico Engels mencionó que más que en un tratado de economía, fue en las páginas de La comedia humana de Balzac donde aprendió y tuvo más elementos para comprender el tránsito del feudalismo al capitalismo y acercarse a la esencia de la decadencia de la aristocracia y el nacimiento de la burguesía. ${ }^{65}$

Es que mediante su creación literaria, el novelista "aspira a que su mentira alcance una verdad más grande de lo que es factible por medio del recuento de hechos". O sea, al buscar un concepto de verdad trascendente a la historia, el novelista transgrede la Historia y aspira a un concepto de verdad inconmensurable con el de la historia ${ }^{66}$ Lo que, como se menciona en los ejemplos anteriores, implica que la literatura puede hacer aportaciones a la historia. Incluso Le Goff recomienda como una novela historiográfica bien lograda $\mathrm{La}$ gloire de l'empire de Jean d'Ormesson y plantea como "una intriga que se [desliza] por los intersticios de la historia" a Ivanhoe, a Los ultimos días de Pompeya, Quo vadis? y Los tres mosqueteros. Pero también considera importante que el historiador señale las libertades que otros se toman con la historia. ${ }^{67}$ Como podemos ver, el problema literario central de la novela historiográfica no es su facilidad de representación: lo que Del Palacio llama la magia de la literatura, sino la que indicó Grützmacher, es decir: "muchos escritores de no-

${ }^{65}$ María Teresa Cortés Zavala, "Historia y literatura”, 126.

${ }^{66}$ E. L. Doctorow, "Apuntes", 8 y 10. Con lo anterior, no se pretende volver al concepto positivista de verdad, decía Nietzsche que "La historiografía, como la ficción, organiza su información para demostrar una intensión" (E. L. Doctorow, "Apuntes", 9.) Novela e historia crean hechos, pero la primera en el sentido de construcción únicamente, la historia es un constructo realizado a través de lo que las evidencias permiten deducir, abducir e inducir sobre lo sucedido. Graciela Velázquez Delgado, "El rol de la abducción peirceana en el proceso de la investigación científica”, Valenciana año 8(15) (enero-junio 2015): 189-213.

${ }^{67}$ Jacques Le Goff, Pensar la historia, 52. Por su parte, Georg Iggers menciona que "Quizá Simon Schama en Certezas absolutas: especulaciones sin garantia y Jonathan Spence en The Question of Hu fueran más lejos en la dirección de una historiografía que disolvía conscientemente la frontera entre la historia especializada y la novela histórica”. Georg Iggers, "Desde la perspectiva de la década de 1990", La historiografía del siglo XX. Desde la objetividad científica al desafio posmoderno (Santiago de Chile: Fondo de Cultura Económica, 2012), 219. Para más información sobre los autores de Ivanhoe y Los tres mosqueteros desde la perspectiva de la "novela histórica" véase Brian Hamnet, "Historias ficticias", 97 y E. L. Doctorow, “Apuntes”, 7. 
vela histórica no voltean a las investigaciones historiográficas ni dialogan con éstas, sino que debaten con la "historia oficial". ${ }^{68}$ Lo cual es entendible porque la historia oficial es en gran parte una ficción, de allí que los literatos se sientan tan cómodos dialogando con ésta.

También el problema se relaciona con otro que es pertinente para la ciencia histórica: la difusión, pues, la historia tiene un bajo impacto social, ${ }^{69}$ "si el pasado es plural, su conocimiento presente es de todos y a todos debe pertenecer. En este sentido, el producto final de una investigación histórica no debe ser sólo el privilegio del conocimiento de un grupo de especialistas" ${ }^{70}$ Tal orientación ética de la historia se opone al de la literatura de forma que la novela historiográfica está vinculada al mercado de un modo que no lo está la investigación historiográfica, lo que coincide con lo que indicó José Emilio Pacheco, para quien la novela es la privatización de la historia. ${ }^{71}$ Empero, si la difusión es uno de los objetivos por los que se recurre a la novela historiográfica, el problema epistemológico fundamental que ésta plantea, al no poder ser entendida más que a partir de su doble oposición y relación con la novela y con la historiografía, es el de la escritura de la historia, es decir, el de la representación de la Historia.

Si bien, el sistemismo y la complejidad consideran que hay muchas descripciones complementarias de la realidad, podemos encontrar diferencias entre la novela y la historiografía: la novela puede ser partidista, la historia busca ser imparcial y a través de la imparcialidad y la intersubjetividad buscar la objetividad; mientras que la novela evoca la intersubjetividad imaginada de la subjetividad del novelista. Lo importante de la novela es la recepción, lo creativo, mientras que la historia no se entiende sin investigación. La novela busca suspenso, intriga; mientras que los elementos que el lector desconocía en una historiografía no siempre son los que está por

${ }^{68}$ Lukasz Grützmacher, "Las trampas”, 158.

${ }^{69}$ Jacques Le Goff, Pensar la historia, 18 y Constanza Toquica, “¿Historia literaria o literatura histórica?, Entrevista con Antonio Rubial”, Fronteras de la Historia, vol. 5 (2000): 126.

${ }^{70}$ Constanza Toquica, “¿Historia literaria”, 127.

${ }^{71}$ Seymour Menton, "La nueva novela”, 32. 
leer. Lo que no excluye que autores como Paul Veyne hagan análisis de sus fábulas (lo que se cuenta) y sus intrigas (el orden en que se cuenta), y que no es carente de utilidad responder iqué lugar tiene la intriga y la retórica en la escritura de la historia? ${ }^{72}$ De modo que en la novela historiográfica se da un entrecruce entre explicación-comprensión/trama-suspenso en la que lo histórico se relativiza y aun así su lectura puede contribuir a generar una conciencia histórica en el lector quien, a menos que suspenda su juicio, es quien decide qué de lo que lee parece ficción y qué historia. ${ }^{73}$

Las novelas historiográficas constituyen laboratorios epistemológicos que permitirían reflexionar cómo aumentar la iconicidad (parecido) de la historiografía con la Historia. Al ser la novela historiográfica hija de su tiempo, también permite comprender las ideas sobre la historia que ostentaban sus autores y las ideas de lo histórico que hicieron circular entre los lectores. A su vez, se recomienda criticar los abusos de tales narraciones, que también pueden considerarse como usos públicos de la historia. Por eso son encomiables historiadores como Celia del Palacio y Antonio Rubial que han escrito novelas historiográficas. De hecho, Rubial plantea implícitamente otro campo de experimentación y reflexión para el laboratorio epistemológico, uno que debe vincularse a lo interdisciplinario, pues, para él un texto no puede llamarse historiográfico "si no se ciñe a ciertas pautas y a algunos límites, los que le impone la realidad personal y social que se pretende" representar. Para él, el autor de ellas debe relacionar su novela "con los aspectos significativos de la época en la que se pretende sucedieron los hechos narrados y que éstos sean reconstruidos con la mayor fidelidad", así como encontrar en las tensiones que son inherentes a la novela historiográfica (que está entre la iconicidad hacia lo real y lo ficticio,

72 Paul Veyne, "En la historia no hay hechos sino 'intrigas”, en Guillermo Zermeño, comp., Pensar la historia. Introducción a la teoría y metodología de la historia (siglo XX), 6577 (México: Universidad Iberoamericana, 1994).

${ }^{73}$ Antonio Rubial, "Historia 'literaria”, 46, 54 y Manuel Alberca, “Umbral”, 11. Sobre la conciencia histórica y su relación para con el conocimiento histórico véase Miguel Ángel Guzmán López, La estructura de la conciencia histórica en clave hermenéuticoontológica (México: Universidad de Guanajuato, 2015). 
entre la veracidad y la veridicción, entre la historia y la literatura), el punto medio. ${ }^{74}$

Pero si la novela historiográfica tiende puentes entre ficción y verdad y, en ella, el novelista y el historiador experimentan con la ficción y la historia decidiendo individualmente dónde empieza y dónde termina cada una, el anhelado punto medio de Rubial es una imposición que no permitiría explorar "los puntos de contacto que la literatura establece" con las diversas historiografías, ${ }^{75}$ especialmente, porque la novela historiográfica es un texto en el que se unen la ficción y la historia de diversas maneras y en distintos grados; lo que implica un amplio espectro de textos híbridos que están entre el polo donde predomina lo ficcional y el polo donde predomina lo historiográfico. Y tal como los colores visibles del arcoíris, que están rodeados de rayos infrarrojos y ultravioletas, fuera del espectro de la novela historiográfica, pero inmediato a él, se encuentran las novelas no historiográficas y las historiografías no noveladas; estas últimas no pueden correr el riesgo de la novela historiográfica: que lo representativo y lo inventado se confunda deliberadamente, es decir, la historiografía. $^{76}$

Este espectro mencionado se modifica con el surgimiento de nuevas obras polares, a la vez que van apareciendo obras en otras partes del mismo espectro. Lo que hace necesario diferenciar las obras ligadas a un extremo del espectro de las ligadas al otro. No se trata de clasificar por clasificar, sino de clarificar conceptos y crear nuevos, pues, son las categorías las que hacen accesible la realidad. Así, habría que considerar la utilidad de subdividir analíticamente el continuum de las novelas historiográficas para poder responder ¿qué tantos compromisos historiográficos tiene una novela?, ¿qué tanto se vincula con los valores, métodos y objetivos de la historia y de la literatura?, y ubicarla entre el polo de la "novela historiográfica" (más cercano a la novela) y el de lo que proponemos, se habría de

${ }^{74}$ Rubial menciona recrear en vez de representar (Antonio Rubial, "Historia 'literaria"”, 46, 47).

75 "Presentación del Dossier Espacios fronterizos: Literatura y Ciencias Sociales". Andamios Revista de Investigación Social 8(15) (enero-abril 2011): 8.

${ }^{76}$ Seymour Menton, "La nueva novela", 24. 
llamar "historia novelada" (más cercano a la historia), ambas con cierta oposición tanto a la novela como a la historiografía de forma que cuestionar las fronteras entre novela historiográfica e historia novelada sería estéril. No porque sean sinónimos, ni conceptos intercambiables, sino porque no podemos decir claramente dónde empieza una y termina la otra. Así que la historiografía novelada buscaría, por ejemplo, representar el pasado estéticamente y así difundirlo exitosamente mientras que la novela histórica utilizaría el pasado como pretexto para contar una historia. Esto es, la primera utilizaría un relato para contar una historia y la segunda utilizaría la historia para contar un relato. ${ }^{77}$

En ambas es el relato el que da sentido, pero sus diferencias pueden ser tan grandes como las que existen, para el espacio ambiguo entre la paleontología y la ficción, entre las películas Caminando con dinosaurios y Parque Jurásico. ${ }^{78} \mathrm{Del}$ mismo modo que una película de divulgación del conocimiento paleontológico como Caminando con dinosaurios que utilizó una narrativa para mostrar verdades científicas no es paleontología, la historiografía novelada tampoco es historiografía. Menos aún si hablamos de novelas historiográficas equivalentes a una película con cierta vinculación a la paleontología como Parque Jurásico, donde el conocimiento paleontológico fue un mero pretexto para la narración.

Esto último es muy apreciable cuando se hace un trabajo comparativo entre novelas históricas que se desenvuelven en un mismo periodo histórico, lo cual denota las diferentes posturas que el autor puede tener al momento de escribir esta clase de narrativa. Por un lado, vemos que algunas tienden a ser precisas al momento de hacer una mimesis de un proceso o hecho histórico y, por otro, existen otras obras que tienden a utilizar dichos eventos como un "pretexto" para desarrollar una narración a partir de "licencias históricas" y recursos literarios, utilizando personajes históricos para crear sensaciones y expectativas en sus lectores.

${ }^{77}$ Es decir, la primera utilizaría la story para contar una history y la segunda utilizaría la history para contar una story.

${ }^{78}$ La primera película fue escrita por John Colle y dirigida por Barry Cook y Neil Nighttingale y la segunda la escribió Michael Crichton y la dirigió Steven Spielverg. 
Un ejemplo de lo dicho anteriormente se puede apreciar al comparar las novelas: Los últimos días de Pompeya (1835) de Edward Bulwer-Lytton y El pompeyano (1986) del historiador alemán Philipp Vandenberg, ya que mientras la primera está fuertemente influenciada por el espiritismo (supuesta ciencia en boga durante el siglo XIX) y el romanticismo, ${ }^{79}$ la segunda intenta ser verosímil, e incluye notas al pie de página en las que el autor explica las licencias poéticas que se tomó y aclara cómo se interpreta desde la historia el acontecimiento narrado, lo que la haría más verídica. ${ }^{80}$ Por lo tanto, vemos como se desarrollaron dos novelas que a pesar de basarse en un mismo acontecimiento histórico, realizan distintas narraciones sobre la forma en que los habitantes de Pompeya percibieron los últimos días de su ciudad, antes de que ésta fuera arrasada por la explosión del monte Vesubio, porque lo hicieron desde una perspectiva distinta, una tomando como base el espiritismo, y un desarrollo narrativo inspirado en la obra de Sir Walter Scott (más apegado a la literatura de ficción convencional), y otra que en contraposición intentó ser más veraz, pero sin dejar del todo el uso de tropos. Se podría excusar lo anterior argumentando el espacio temporal existente entre la publicación de una y otra novela, sin embargo, ésta es una problemática constante en el análisis comparativo de este tipo de narrativa.

En suma, apreciamos que así como no existe un consenso entre los críticos literarios y los científicos sociales en cuanto al concepto de "novela histórica", tampoco lo hay entre quienes la escriben. Esto sucede porque hay distintos objetivos de estos tipos de narraciones: o intenta ser un medio de difusión accesible a un público mayor, o

${ }^{79}$ Como el autor menciona en el prólogo de su obra. Edward Buwler-Lytton, Los últimos dias de Pompeya, dias de Pompeya (Madrid: Casa Editorial Saturnino Calleja Fernández, 1978), 7-12.

${ }^{80} \mathrm{El}$ autor, en el epilogo de su obra, hace una serie de aclaraciones con respecto a las licencias poéticas que se tomó, como el hecho de que aunque en su novela era de noche, al hacer erupción el monte Vesubio, en la realidad fue al medio día. Al mismo tiempo, hace un comentario crítico de la forma de escribir del antes mencionado Edward BuwlerLytton, llamándolo escritor de novelas policiacas y espiritistas, una tendencia de finales del siglo xIx. Philipp Vandenberg, El pompeyano (Buenos Aires: Javier Vergara Ediciones, 1987), 329-330. 
busca crear sensaciones y experiencias estéticas con base en la deconstrucción de situaciones y personajes bien conocidos, e incluso mitificados, dentro de una cultura. Desde la historia podemos llamar el primer tipo historia novelada, mientras que el segundo tipo de novela, se llamaría novela historiográfica. Precisión que se hace a sabiendas de que desde la literatura no existe la necesidad de hacer esa diferenciación porque historia y literatura presentan inconmensurabilidades.

\section{Conclusión}

Moretti plantea que lo que necesita la historia literaria son problemas carentes de solución, para enfrentarnos "con los límites y las lagunas de nuestro conocimiento" ${ }^{81}$ Algo con lo que coincidiría Margaret Somers, para quien hay que investigar los conceptos que no encontramos como controversiales y buscar allí "las redes conceptuales con las que los conceptos se construyen y constrińen", pero como los conceptos no existen como categorías autónomas su examen debe ser intersubjetivo, sin esencializar los términos, que son históricos siempre. Después de todo, "en historia muchos de los mejores descubrimientos se logran en el límite con otras disciplinas". ${ }^{82}$ Así que las novelas historiográficas no deben ser estudiadas y criticadas sólo bajo el criterio de verdad de la historiografía, pues, aunque están ligadas a la historia, no dejan de ser novelas y han de ser examinadas desde una perspectiva crítica e interdisciplinaria tanto por investigadores literarios como por investigadores de la Historia, ya sea que se posicionen unos u otros en las humanidades o en las ciencias sociales. Hay que torear al toro en ambos terrenos (historia y literatura) ${ }^{83}$ sea que coincidamos con Michel de Certeau, para quien la historia no es ciencia ${ }^{84} \mathrm{o}$ que sigamos a Car-

${ }^{81}$ Franco Moretti, La literatura, 45.

${ }^{82}$ Margaret R. Somers, "What's Political”, 115, 130, 132, 134-136 y Luis Medina Peña, "Historia contemporánea”, 309.

${ }^{83}$ Ana María Alba Villalobos, "Géneros de frontera”, 33.

${ }^{84}$ Entre otras cosas porque las reglas de su producción son implícitas (François Dosse, "La biografía" 68, 99). Hemos de decir que en historia hay procedimientos implícitos, por ejemplo, en su citación. Tenemos la alternativa de buscar la obra o archivo que cita el 
los Aguirre, para quien "La verdadera historia es necesariamente crítica", restituye "la complejidad de la vida en el pasado, tal como esa complejidad se nos aparece en el presente". ${ }^{85}$

La categoría novela histórica es una convención literaria y carece de operatividad para la historia que se hace desde las ciencias sociales. Al respecto, las categorías paleonovela, novela historiográfica e historia novelada serían operativas para la historiografía. ${ }^{86}$ Además, se puede concluir que para que un trabajo de ciencias sociales sea historiografía, no debe ser novela; en cuanto a la historia que se hace desde las humanidades, la respuesta no puede ser tan contundente. En ambos casos la historia requiere de mayor reflexividad, pues, las categorías que usemos han de cambiar conforme ampliemos el conocimiento del mundo social y seamos reflexivos con las mismas categorías. La reflexividad es en sí misma un desafío a los fundamentos epistemológicos de la historia misma, que a su vez es cada vez menos autónoma como disciplina y cada vez más interdependiente, lo cual no debe significar una aceptación acrítica de toda heterorreflexividad que se le presente.

Las ciencias y las humanidades han de voltear hacia sí mismas para examinar las herramientas conceptuales de investigación que frecuentemente se dan por sentado y formar unas bases más firmes para el diálogo intradisciplinario e interdisciplinario. ${ }^{87} \mathrm{~A}$ partir de

autor o confiar en él; pero también en las ecuaciones matemáticas está la opción entre confiar que su resultado es correcto o comprobar la ecuación.

${ }^{85}$ Carlos Antonio Aguirre Rojas, "La biografía".

${ }^{86}$ Pedro Viqueira menciona que las ciencias sociales (aunque en realidad también todas las ciencias) señalan y traspasan los límites del sentido común, ya que rompen los estereotipos y las simplificaciones no científicas. Juan Pedro Viqueira, "Una historia en construcción”, 345.

${ }^{87}$ Margaret R. Somers, “What's Political”, 114, 115, 130, 132, 137. En ese sentido, Antonio Rubial considera que "Los metodólogos que sólo hacen teoría y que no van a un archivo, hacen muy bonita teoría, pero no están haciendo historia, porque no están basándose en los documentos", realiza una reflexión sólo sobre un nivel de la historia, sin reflexionar en el nivel epistemológico. De haberlo hecho, se daría cuenta que lo que plantea por un criterio metodológico que no es historia sí lo es en un contexto de reflexividad y teniendo en cuenta que no hay observaciones puras, sino que la historia está constituida de observaciones de observaciones sobre la Historia. Así que habría que poner cuidado de no conformarnos con reflexionar en un nivel sin pensar que necesitamos reflexionar también en otro u otros (Constanza Toquica, "¿Historia literaria”, 124). 
tal diálogo, las novelas historiográficas y las historias noveladas podrán seguir descubriendo reglas implícitas de lo historiográfico y lo novelesco, rompiéndolas. ${ }^{88}$

\section{BibliografíA}

Aguirre Rojas, Carlos Antonio. "La biografía como género histórico", Correo del Maestro (45) (febrero 2000).

Alba Villalobos, Ana María. "Géneros de frontera entre la historia y la literatura. Un espacio obligado para el trabajo interdisciplinario". En Reflexiones sobre historia e interdisciplina. Planteamientos teóricos, metodológicos y estudios de caso, coord. Graciela Bernal Ruiz, 19-45. Guanajuato: Universidad de Guanajuato, 2012.

AlberCa, Manuel. "En las fronteras de la autobiografia". En II Seminario de "Escritura autobiográfica", coord. Manuela Ledesma Pedraz, 53-63. Jaén: Universidad de Jaén, 1999.

. "Umbral o la ambigüedad autobiográfica”. Círculo de Lingüistica Aplicada a la Comunicación (CLAC) (50) (2012): 3-24, http://www.ucm.es/info/circulo/no50/alberca.pdf (Fecha de consulta: 20 de marzo de 2014).

Appleby, Joyce, Lynn Hunt y Margaret Jасов. La verdad sobre la historia. Barcelona: Editorial Andrés Bello, 1994.

Barros, Carlos. "Oficio de historiador, ¿nuevo paradigma o positivismo?" Historia a Debate. http://www.h-debate.com/cbarros/ spanish/articulos/nuevo_paradigma/oficio.htm (Fecha de consulta: 17 de febrero de 2016).

Bulwer-Litton, Edward George. Los últimos días de Pompeya. Madrid: Casa Editorial Saturnino Calleja Fernández, 1976.

Burrow, John. "El siglo xx. Profesionalidad y la crítica de la "historia whig". La historia como ciencia y la historia como arte". Historia de las Historias. De Heródoto al siglo XX. Barcelona: Crítica, 2009, 551-609.

${ }^{88}$ Michael O’Toole, “Thinking with your own eyes: Magritte and the Logical Metafunction", Systemic Functional Linguistics in Use. Odense Working Papers in Language and Communication, vol. 29 (2008): 67. 
. "Un consenso profesional: la influencia alemana". Historia de las Historias. De Herodoto al siglo XX. Barcelona: Crítica, 2009, 535-550.

Clemens, Elisabeth S. “Towards a Historicezed Sociology: Theorizin Events, Processes, and Emergence”. Annual Review of Sociology, vol. 33 (2007): 527-549.

Corbalán, Ana. "Metaficción historiográfica en la novela española del siglo xxi: Hacia una reconstrucción del pasado nacional”, Cuaderno Internacional de Estudios Humanisticos y Literatura, vol. 16 (otońo 2011): 22-34.

Cortés Zavala, María Teresa. "Historia y literatura: una relación invisible”. En La historia y su relación con otras disciplinas, coord. José Alfredo Uribe Salas y María Teresa Cortés Zavala, 115-126. Morelia: UMSNH, 2003.

Cracraft, James. "History as philosophy". History and Theory (54) (febrero 2015): 45-68.

DATRI, Edgardo y Gustavo CóRDOBA. Introducción a la problemática epistemológica. Una perspectiva didáctica de las tensiones en la Filosofía de la Ciencia. Rosario: Homo Sapiens, 2004.

Doctorow, Edgar Lawrence. "Apuntes sobre historia de la ficción ¿Quién cambiaría la Ilíada por la "verdadera" fuente histórica?" Historias (69) (enero- abril 2008): 3-10.

Dosse, François. "La biografía, un género impuro". El arte de la biografía. México: UIA, 2007, 55-121.

. "La prehistoria de Annales". La historia en migajas. De Annales a la nueva historia. México: Universidad Iberoamericana, 2006, 27-61.

. "Los tiempos de Marc Bloch y Lucien Febvre". La historia en migajas. De Annales a la nueva historia. México: Universidad Iberoamericana, 2006, 62-95.

Dube, Saurabh. "Identidades culturales y sujetos históricos: estudios subalternos y perspectivas poscoloniales". Estudios de Asia y África 45(2) (mayo-agosto 2010): 251-292.

Ginzburg, Carlo. "Microhistoria: dos o tres cosas que sé de ella". Manuscrits (12) (enero 1994): 13-42.

Gonzalbo Aizpuru, Pilar. "En torno a intimidades y rutinas la 
nueva historiografía de lo cotidiano". En Cincuenta años de investigación histórica en México, coord. Gisela von Wobeser, 6979. México: unAM, ug, 1998.

GONZÁLEZ y GonZÁLEZ, Luis. "La novela como historia verídica". En Historia y novela histórica, coord. Conrado Hernández López, 25-29. México: Colegio de Michoacán, 2004.

Grinberg Pla, Valeria. "La novela histórica de finales del siglo xx y las nuevas corrientes historiográficas". Áncora (11 de marzo de 2001) http://wvw.nacion.com/ancora/2001/marzo/11/historia2.html (Fecha de consulta: 3 de marzo de 2014).

GrüTZMACHER, Lukasz. "Las trampas del concepto 'la nueva novela histórica’ y de la retórica de la historia postoficial”. Acta Poética 27(1) (primavera 2006): 141-167. https://revistas-filologicas. unam.mx/acta-poetica/index.php/ap/article/view/193/192 (Fecha de consulta: 3 de marzo de 2014).

GuzMán López, Miguel Ángel. La estructura de la conciencia histórica en clave hermenéutico-ontológica. México: Universidad de Guanajuato, 2015.

Guzmán López, Miguel Ángel e Ignacio Camarena Navarro. "Entre Julio Verne y Jorge Ibargüengoitia. Dos estudios interdisciplinarios entre la historia y la literatura". En Reflexiones sobre historia e interdisciplina. Planteamientos teóricos, metodológicos y estudios de caso, coord. Graciela Bernal Ruiz, 181-196. Guanajuato: Universidad de Guanajuato, 2012.

Hacking, Ian. Representar e intervenir. México: Paidós, Unam, 1996.

Hamnet, Brian. "Historias ficticias: el dilema de los hechos y la imagen en la novela histórica del siglo XIx". En Historias (69) (enero-abril 2008): 97-120.

Hernández López, Conrado. "Introducción: tendencias y corrientes de la historiografía mexicana del siglo xx". En Tendencias y corrientes de la historiografía mexicana del siglo XX, coord. Conrado Hernández López, 11-32. México: Colegio de Michoacán, UNAM, 2003.

Hobsbawm, Eric. "Todos los pueblos tienen historia”. Sobre la historia. Barcelona: Biblioteca de bolsillo, 2004, 177. 
IGGERS, Georg. "Desde la perspectiva de la década de 1990". La historiografia del siglo XX. Desde la objetividad cientifica al desafio posmoderno. Santiago de Chile: Fondo de Cultura Económica, 2012, 217-226.

"El 'giro lingüístico', ¿El fin de la historia como disciplina académica?". La historiografía del siglo XX. Desde la objetividad cientifica al desafio posmoderno. Santiago de Chile: Fondo de Cultura Económica, 2012, 193-215.

. "Francia: La escuela de los Annales". La historiografía del siglo XX. Desde la objetividad cientifica al desafio posmoderno. Santiago de Chile: Fondo de Cultura Económica, 2012, 87-107.

KaYE, Harvey J. "E.P. Thompson: la formación de la clase trabajadora inglesa". Los historiadores marxistas británicos. Un análisis introductorio. Zaragoza: Universidad de Zaragoza, 1989, 153-198.

"Introducción". Los historiadores marxistas británicos. Un análisis introductorio. Zaragoza: Universidad de Zaragoza, 1989, 3-21.

KuImovsкy, Gregorio. Las desventuras del conocimiento cientifico. Una introducción a la epistemología. Buenos Aires: A-Z editora, 1997.

Kunn, Thomas S. La tensión esencial. Estudios selectos sobre la tradición y el cambio en el ámbito de la ciencia. Madrid: Fondo de Cultura Económica, 1982.

LACERDA, Ruben Gomes. "Interstícios e interfaces entre a história e a literatura: uma nova velha discussão". En Escrita da história, org. João Edson de Arruda Fanaia, Osvaldo Mariotto Cerezer, Renilson Rosa Ribeiro. Cáceres: Unemat, 2010.

Le Goff, Jacques. Pensar la historia. Modernidad, presente, progreso. Barcelona: Paidós, 2005.

LeVI, Giovanni. "Sobre microhistoria". En Formas de hacer Historia, Peter Burke et al., 119-143. Madrid: Alianza Editorial, 1993.

López FACAL, Ramón. "La enseñanza de la historia, más allá del nacionalismo". En Usos públicos de la Historia, ed. José Carreras Ares y Carlos Forcadell Âlvarez, 223-255. Madrid: Marcial Pons Ediciones de Historia, 2003.

Mahoney, James. "Revisiting General Theory in Historical Sociology”. Social Forces 83(2) (2004): 459-489. 
Maestro González, Pilar. "El modelo de las historias generales y la enseñanza de la historia: límites y alternativas". En Usos públicos de la Historia, ed. José Carreras Ares y Carlos Forcadell Álvarez, 173-221. Madrid: Marcial Pons Ediciones de Historia, 2003.

Matute, Álvaro. "La historia inmediata". Revista de la Universidad de México (492-493) (enero-febrero 1992): 61-63.

MaYer, Benjamín E. "Perdurabilidad de la historia en Jacques Derrida”. En Cincuenta años de investigación histórica en México, coord. Gisela von Wobeser, 59-67. México: UnAM, UG, 1998.

Medina PeÑa, Luis. "Historia contemporánea itema de historiadores?". En Cincuenta años de investigación histórica en México, coord. Gisela von Wobeser, 295-311. México: UNAM, UG, 1998.

Menton, Seymour. "La nueva novela histórica: definiciones y orígenes". En La nueva novela histórica de la América Latina, 19791992, 29-66. México: Fondo de Cultura Económica, 1993.

Mignolo, Walter D. Elementos para una teoría del texto literario. Barcelona: Editorial Crítica, 1978.

Morales Jasso, Gerardo. "La creación de México. Una revisión historiográfica sobre la Independencia”. Tesis de Licenciatura en Historia, Universidad Autónoma de San Luis Potosí, marzo 2013.

. "El discutible carácter de las formas de hacer historia: ¿ciencias o humanidades? Una propuesta no dualista". Legajos (5) (enero-marzo 2015): 47-70.

Moretti, Franco. La literatura vista desde lejos. Barcelona: Morbot Ediciones, 2005.

O'Gorman, Edmundo. "El arte o de la monstruosidad". En El arte o de la monstruosidad y otros escritos, 71-88. México, Planeta, Conaculta, 2002.

. "La historia como búsqueda del bienestar. Un estudio acerca del sentido y el alcance de la tecnología". En El arte o de la monstruosidad y otros escritos, 21-56. México: Planeta, Conaculta, 2002.

Ortiz Monasterio, José. “Dos discursos patrios de Vicente Riva Palacio. Un caso para evaluar la aportación de la novela histórica 
como método de conocimiento". Historias (69) (enero-abril 2008): 57-79.

O’Toole, Michael. "Thinking with your own eyes: Magritte and the Logical Metafunction”. Systemic Functional Linguistics in Use. Odense Working Papers in Language and Communication, vol. 29 (2008): 63-84.

Palacio Montiel, Celia del. "Leona Vicario, entre la historia y la ficción”. Revista Campus Milenio (7 de enero de 2011): 27-28.

. "La novísima novela histórica en México. Una revisión de las más recientes tendencias". En Negociando identidades, traspasando fronteras, ed. Susanne Igler y Stauder Thomas, 201-213. Madrid: Iberoamericana-Vervuert, 2008.

Pappe, Silvia y María Luna Argudín. Historiografía critica. Una reflexión teórica. México: UAM-A, 2001.

Paso, Fernando del. "Novela e historia". En Historia y novela histórica, coord. Conrado Hernández López, 88-99. México: Colegio de Michoacán, 2004.

PiazzA, Alberto. "La evolución vista desde cerca". En La literatura vista desde lejos, Franco Moretti, 131-154. Barcelona: Morbot Ediciones, 2005.

"Presentación del Dossier Espacios fronterizos: Literatura y Ciencias Sociales". Andamios Revista de Investigación Social 8(15) (enero-abril 2011): 7-12, http://www.scielo.org.mx/scielo. php?script=sci_arttext\&pid=S1870-00632011000100001\&ln $\mathrm{g}=\mathrm{pt} \& \mathrm{nrm}=\mathrm{iso}$ (Fecha de consulta: 21 de marzo de 2014).

Ramírez Cobián, Mario Teodoro. "Recuperar la historia. La alternativa hermenéutica al concepto de la historia científica”. En $L a$ historia y su relación con otras disciplinas, coord. José Alfredo Uribe Salas y María Teresa Cortés Zavala, 15-44. Morelia: UMSNH, 2003.

Revueltas, Eugenia. "Historia y literatura. Entre el conocimiento y el saber". En Historia y novela histórica, coord. Conrado Hernández López, 273-289. México: Colegio de Michoacán, 2004.

Rubial, Antonio. "Historia 'literaria' versus Historia 'académica". en El historiador frente a la historia. Historia y literatura, F. Navarrete, A. Rubial et. al., 41-60. México: UnAM, 2000. http://es. 
scribd.com/doc/143802041/Antonio-B-Rubial-Garcia-Historia-literaria-versus-historia-academica (Fecha de consulta: 3 de marzo de 2014).

SAITTA, Armando. Guía crítica de la historia y de la historiografía. México: Fondo de Cultura Económica, 1989.

SANDERs, Karen. "La tradición y la nación". En Nación y tradición. Cinco discursos en torno a la nación peruana, 1885-1930, 83-122. Lima: Pontificia Universidad Católica del Perú, Fondo de Cultura Económica, Fondo Editorial de Cultura, 1997.

Serna, Enrique. "Santa Anna en la historia y en la ficción". En Historia y novela histórica: coincidencias, divergencias y perspectivas de análisis, coord. Conrado Hernández López, 167-182. Zamora: El Colegio de Michoacán, 2004.Somers, Margaret R. "What's Political or Cultural about Political Culture and the Public Sphere? Toward an Historical Sociology of Concept Formation". Sociological Theory 13(2) (1995): 113-144.

STOLER, Ann Laura. "Archivos coloniales y el arte de gobernar". Revista Colombiana de Antropología 6(2) (2010): 465-496.

Toquica, Constanza. “‘Historia literaria o literatura histórica?’ Entrevista con Antonio Rubial". Fronteras de la Historia (5) (2000): 121-144.

Uribe Salas, José Alfredo y María Teresa Cortés Zavala. “Introducción”. En La historia y su relación con otras disciplinas, coord. José Alfredo Uribe Salas y María Teresa Cortés Zavala, 15-44. Morelia: Universidad Michoacana de San Nicolás de Hidalgo, 2003.

VAndenberg, Philipp. El pompeyano. Buenos Aires: Javier Vergara Ediciones, 1987.

Vargas Llosa, Mario. La verdad de las mentiras. Madrid: Punto de Lectura, 2007, 15-32.

VelázQuez Delgado, Graciela. "El rol de la abducción peirceana en el proceso de la investigación científica”. Valenciana, año 8(15) (enero-junio 2015): 189-213.

. "Un espacio abierto: la interdisciplina en algunas corrientes historiográficas del siglo xx". En Reflexiones sobre historia e interdisciplina. Planteamientos teóricos, metodológicos y estudios de caso, 
coord. Graciela Bernal Ruiz, 47-73. Guanajuato: Universidad de Guanajuato, 2012.

Vergara Anderson, Luis. "La historia y su escritura en tiempo y narración de Paul Ricoeur". En Cincuenta años de investigación histórica en México, coord. Gisela von Wobeser, 19-30. México: UNAM, UG, 1998.

VeYne, Paul. "En la historia no hay hechos sino 'intrigas"'. En Pensar la historia. Introducción a la teoría y metodología de la historia (siglo XX), comp. Guillermo Zermeño, 65-77. México: Universidad Iberoamericana, 1994.

Viqueira, Juan Pedro. "Una historia en construcción. Teoría y práctica de los desfases". Anuario del Centro de Estudios Superiores de México y Centroamérica 2000, San Cristóbal de las Casas: Universidad de Ciencias y Artes de Chiapas, Centro de Estudios Superiores de México y Centroamérica, 2002, 341-379. 